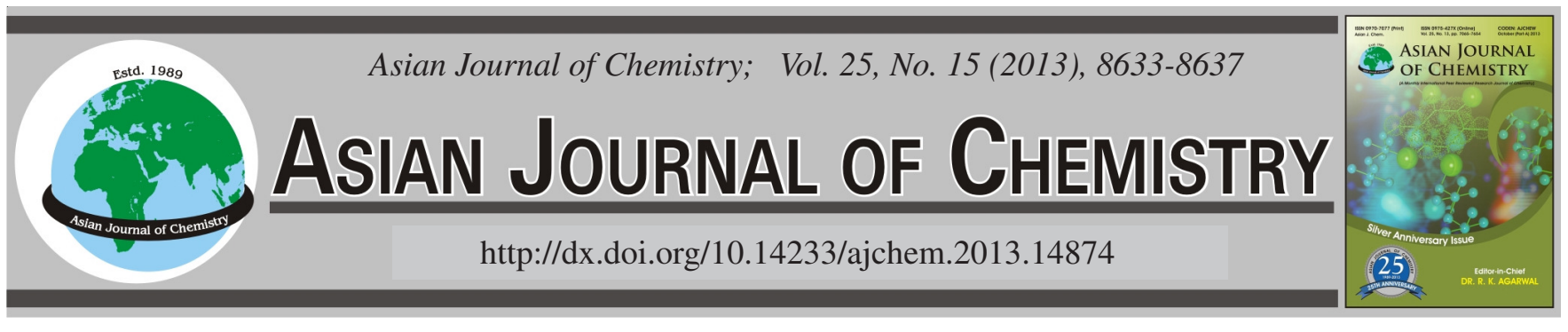

\title{
Cinnamic Acid Derivatives via Heck Reaction in an Aqueous- Biphasic Catalytic System with Easy Catalyst-Product Separation
}

\author{
S.V. JAGTAP* and R.M. DEShPANDE
}

Chemical Engineering Division, National Chemical Laboratory, Dr. Homi Bhabha Road, Pune- 411 008, India

*Corresponding author: Fax: +91 20 25902621; Tel: +91 20 25902620; E-mail: sangeetajagtap@ rediffmail.com

\begin{abstract}
A true biphasic [aqueous-organic] system for the coupling of water soluble sodium acrylate with different aryl halides for the synthesis of cinnamic acid derivatives has been developed, employing palladium catalysts that is soluble in organic phase. Amongst them, palladacycle was found to be stable in presence of water and could be recycled for four times with no loss in the activity. Such a system facilitates easy recycle of catalyst and also the removal of the salts from the catalyst phase, ensuring high activity with respect to cumulative turn over number (TON) and turn over frequency (TOF). The reaction was facilitated by organic as well as inorganic bases. The efficiency of the catalyst, role of organic/inorganic bases on the activity is reported.
\end{abstract}

Key Words: Heck reaction, Biphasic catalysis, Palladacycle, Separation.

\section{INTRODUCTION}

Catalyst product separation has always been a major issue in process development involving homogeneous catalysts ${ }^{1,2}$. With particular reference to Heck reactions, the multi-component system comprising olefin, aryl halide, vinylated product, base, base-halide adduct, phase transfer agent, catalyst and generally a polar solvent, requires a complex strategy for product separation and catalyst recovery ${ }^{3}$ and recycle. Although the extremely active and stable palladacycle catalysts give highly enhanced rates ${ }^{4,5}$, conventional strategies of catalystproduct separation still need to be followed, which could lead to catalyst deactivation. There are no details on the recycle of palladacycle catalyst for Heck reaction in the reported literature. To overcome the issues of catalyst-product separation, the use of biphasic systems has been reported for Heck reactions ${ }^{6-10}$, which involves non-aqueous or aqueous biphasic systems. The non-aqueous biphasic system ${ }^{6-8}$ generally uses a polar solvent like ethylene glycol as the catalyst phase and employs a water-soluble catalyst. A number of reports on the application of water-soluble catalysts for Heck reactions ${ }^{9-12}$ in aqueous media have shown the effectiveness of these systems for the coupling reaction of different aryl halides and olefins. The presence of water is also reportedly beneficial for the Heck reaction $^{12-16}$. The solubilization of the base in the reaction medium is enhanced in presence of water leading to improved activity ${ }^{17-19}$. As per the reported mechanism of Heck reaction, water also helps removal of the halide to generate the active catalytic species ${ }^{20}$. However, in a majority of the studies a detailed investigation on the catalyst recycle is not available for Heck reaction in aqueous media.

Heck reactions of water-soluble olefins like sodium acrylate are amenable to reactions in aqueous-organic biphasic systems using Pd complex catalysts solubilized in the organic phase. Such a biphasic system offers more advantages over conventional systems with respect to catalyst recycle and product recovery. The presence of water ensures an efficient removal of the halide byproduct, formed in the course of the Heck coupling of sodium acrylate with different aryl halides.

The Heck reaction of acrylic acid salts with aryl halides as shown in Scheme-I, results in the synthesis of substituted cinnamic acid derivatives, which have wide ranging applications as UV absorbers, antioxidants in plastics, as intermediates for pharmaceuticals ${ }^{21}$ and also in medicinal chemistry ${ }^{22,23}$.

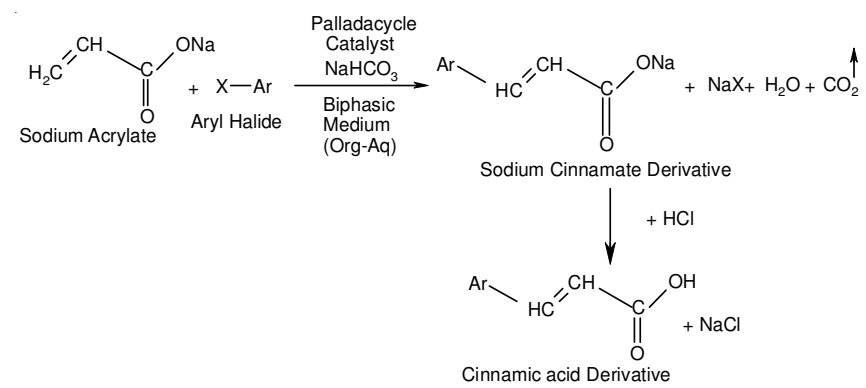

Scheme-I: Heck reaction of acrylic acid salts with aryl halides followed by isolation of product 
Since the alkali metal salts of the acrylic acid are watersoluble, a biphasic system can be set up, with the catalyst in the organic phase and the olefin in the aqueous phase as shown in Fig. 1. The use of a biphasic medium for the Heck reaction of the water-soluble sodium acrylate offers distinct advantages specially tuned to the water-soluble products. These are (i) the product formed is a Sodium salt of cinnamic acid derivative, which is soluble in water and can be recovered easily (ii) the base/ base-HX adduct is also soluble in water and is removed from the catalyst phase and (iii) the organic phase consisting of catalyst and the residual aryl halide can be recycled by mere phase separation.

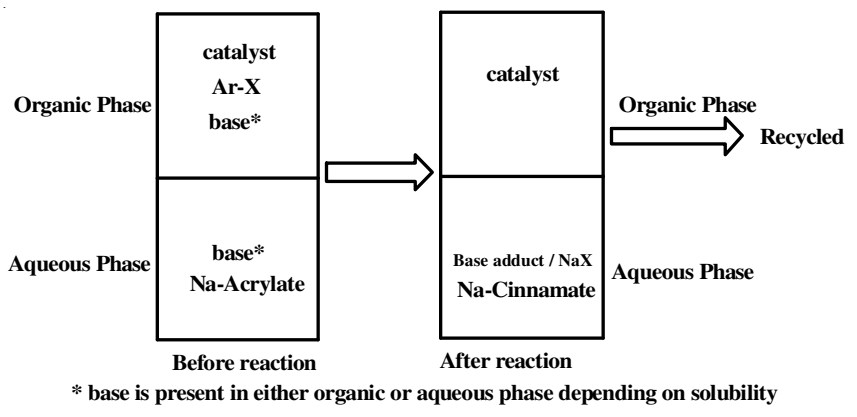

Fig. 1. A schematic of the two-phase system

We demonstrate here the Heck coupling of acrylic acid salts with aryl halides using an aqueous-organic biphasic system in the presence of palladacycle catalyst. The role of organic and inorganic bases on the activity of the catalyst has also been investigated. The stability of the catalyst on recycle has been demonstrated for a few recycles with no loss in the activity. The products in each case were isolated and formation of the respective product was confirmed.

\section{EXPERIMENTAL}

The palladium complexes of the type $\mathrm{PdCl}_{2} \mathrm{~L}$, [where $\mathrm{L}=$ DPPE, 2,2'-bipyridine, $\left(\mathrm{PPh}_{3}\right)_{2}$ and $\mathrm{Py}_{2}$ ] and the palladacycle were prepared by standard procedures ${ }^{5,24,25}$. The bases used (AR grade) were purchased from M/s Loba Chemicals, India. Sodium acrylate and all aryl halides procured from Aldrich, USA, were used as such. The solvents were obtained from $\mathrm{M} / \mathrm{s}$ SDs Chemicals India. Quantitative analysis of the aryl halide consumed was done on GC (Agilent 6850 series II), using a HP-1 capillary column. In case of product the isolated yield was observed. The products i.e. cinnamic acid derivatives were isolated from the aqueous solutions by acidification as depicted in Scheme-I. The derivatives of cinnamic acid were precipitated and were identified by using GCMS (Agilent $6890 \mathrm{~N}$ series equipped with 5973N Mass Selective Detector). The reactions were conducted in a high-pressure autoclave of $50 \mathrm{~mL}$ capacity manufactured by M/s Amar Engineering, Mumbai.

General procedure for Heck reaction: Aryl halide (3 $\mathrm{mmol})$ and catalyst $(0.003 \mathrm{mmol})$ were dissolved in toluene $(15 \mathrm{~mL})$. Sodium acrylate $(3.3 \mathrm{mmol})$, base $(3.0 \mathrm{mmol})$ and water $(15 \mathrm{~mL})$ were mixed separately. Both organic and aqueous phases were then added into the autoclave. The reaction was carried out at $150{ }^{\circ} \mathrm{C}$ with 1450 -rpm agitation for a period of $0.5 \mathrm{~h}$. The reaction mixture was cooled and the aqueous layer was treated with dilute $\mathrm{HCl}$ till it was acidic to litmus. The precipitate was filtered, washed with $3 \mathrm{~mL} \times 5 \mathrm{~mL}$ of water and dried under vacuum. The products obtained were the derivatives of cinnamic acid.

For recycle study, the catalyst phase (organic phase) was separated by simple phase separation and used in the above procedure along with a fresh aqueous phase consisting of substrates and base.

Detection method: The organic phase of the reaction mixture was analyzed using GC (Agilent 6850 series II), controlled by the HP Chemstation software, on an HP1 column. The conversion of iodobenzene was monitored along with the isolated yields of cinnamate derivatives. The products formed during the reaction were identified using GC-MS (Agilent GC 6890 with 5973 mass selective detector instrument).

\section{RESULTS AND DISCUSSION}

The palladium complexes of the type $\mathrm{PdCl}_{2} \mathrm{~L}$, [where $\mathrm{L}=$ DPPE, 2,2'-Bipy, $\left(\mathrm{PPh}_{3}\right)_{2}$ and $\left.\mathrm{Py}_{2}\right]$ and the palladacycle transdi( $m$-acetato)-bis[o-(di-o-tolylphosphino)benzyl] dipalladium(II) were screened for their activity in the Heck coupling of sodium acrylate with iodobenzene in an aqueous-organic biphasic medium in presence of the base $\mathrm{Na}_{2} \mathrm{CO}_{3}$. The results are presented in Table-1 [Entry 1-5].

When the reaction was conducted in the absence of any ligand with only $\mathrm{PdCl}_{2}$ as a catalyst, it was found to precipitate and the activity observed was due to the Pd metal rather than a truly homogeneous catalyst. Of the different Pd-complexes investigated, the highest activity was observed for the palladacycle complex. The activity of the $\mathrm{PdCl}_{2}$ (DPPE) complex was almost similar to that observed for $\mathrm{PdCl}_{2}\left(\mathrm{PPh}_{3}\right)_{2}$ complex. Phosphine ligands can stabilize the active catalyst in Heck reactions thus making them more active for the reaction. $\mathrm{PdCl}_{2}(\mathrm{Py})_{2}$ gave lower activities as compared to the other catalysts. Surprisingly, the $\mathrm{PdCl}_{2}$ (bipy) complex was found to be as active as the phosphine complexes. Bidentate ligands are known to stabilize the catalytic complexes and this is probably the reason for the observed rates with the $\mathrm{PdCl}_{2}$ (bipy) catalyst. No precipitation of the Pd metal was observed in any of the reactions with the $\mathrm{Pd}$ complex catalysts. No leaching of the metal to the aqueous phase was also observed, as confirmed by the ICP analysis of the aqueous phase.

Since the Hermann's palladacycle catalyst had the highest activity, a detailed screening of bases was conducted using this catalyst in an aqueous-organic (water-toluene) medium. The results presented in Table-1 [Entry 5-12] show the activities observed for the different inorganic and organic bases screened. The inorganic bases such as carbonate, bicarbonate and hydroxides gave the best activity, as compared to the inorganic acetates and organic amines. This trend is different from that observed in homogeneous catalytic systems wherein the acetate salts give good activities in polar solvents like NMP, DMF etc, which is also further enhanced in the presence of phase transfer agents like quaternary ammonium halides ${ }^{26}$. The acetates are relatively more soluble in polar solvents compared to the carbonates, bicarbonates and hydroxides and hence they give better turn over frequency. In aqueous systems the solubility issues are not so important, as all these bases are water-soluble 


\begin{tabular}{|c|c|c|c|c|c|c|c|}
\hline \multicolumn{8}{|c|}{$\begin{array}{l}\text { TABLE-1 } \\
\text { SCREENING OF CATALYSTS, BASE AND ARYL HALIDE FOR THE HECK REACTION } \\
\text { OF SODIUM ACRYLATE IN AQUEOUS-ORGANIC BIPHASIC MEDIUM }\end{array}$} \\
\hline Sr. No. & Catalyst & Base & Aryl halide & Isolated product & Conversion $(\%)$ of iodobenzene & TON & $\operatorname{TOF}\left(\mathrm{h}^{-1}\right)$ \\
\hline 1 & $\mathrm{PdCl}_{2}$ (DPPE) & $\mathrm{Na}_{2} \mathrm{CO}_{3}$ & Iodobenzene & 1 & 65 & 649 & 1298 \\
\hline 2 & $\mathrm{PdCl}_{2}\left(\mathrm{PPh}_{3}\right)_{2}$ & $\mathrm{Na}_{2} \mathrm{CO}_{3}$ & Iodobenzene & 1 & 63 & 628 & 1256 \\
\hline 3 & $\mathrm{PdCl}_{2}$ (Bipy) & $\mathrm{Na}_{2} \mathrm{CO}_{3}$ & Iodobenzene & 1 & 62 & 617 & 1234 \\
\hline 4 & $\mathrm{PdCl}_{2}(\mathrm{Py})_{2}$ & $\mathrm{Na}_{2} \mathrm{CO}_{3}$ & Iodobenzene & 1 & 33 & 335 & 670 \\
\hline 5 & Palladacycle & $\mathrm{Na}_{2} \mathrm{CO}_{3}$ & Iodobenzene & 1 & 93 & 930 & 1860 \\
\hline 6 & Palladacycle & $\mathrm{NaHCO}_{3}$ & Iodobenzene & 1 & 84 & 892 & 1784 \\
\hline 7 & Palladacycle & $\mathrm{NaOH}$ & Iodobenzene & 1 & 84 & 886 & 1772 \\
\hline 8 & Palladacycle & ${ }^{\mathrm{a}} \mathrm{Na}_{2} \mathrm{CO}_{3}$ & Iodobenzene & 1 & 84 & 825 & 1650 \\
\hline 9 & Palladacycle & $\mathrm{NaOAc}$ & Iodobenzene & 1 & 41 & 434 & 868 \\
\hline 10 & Palladacycle & KOAc & Iodobenzene & 1 & 38 & 406 & 812 \\
\hline 11 & Palladacycle & $\mathrm{Et}_{3} \mathrm{~N}$ & Iodobenzene & 1 & 32 & 292 & 584 \\
\hline 12 & Palladacycle & Morpholine & Iodobenzene & 1 & 26 & 288 & 576 \\
\hline 13 & Palladacycle & $\mathrm{Na}_{2} \mathrm{CO}_{3}$ & 4-Iodoanisole & 2 & 94 & 939 & 1878 \\
\hline 14 & Palladacycle & $\mathrm{Na}_{2} \mathrm{CO}_{3}$ & 4-Bromotoluene & 3 & 1 & 10 & 20 \\
\hline 15 & Palladacycle & $\mathrm{Na}_{2} \mathrm{CO}_{3}$ & Bromobenzene & 1 & 1 & 12 & 24 \\
\hline 16 & Palladacycle & $\mathrm{Na}_{2} \mathrm{CO}_{3}$ & Chlorobenzene & - & No reaction & - & - \\
\hline
\end{tabular}

Reaction conditions: Organic phase: $\mathrm{ArX}(3.0 \mathrm{mmol})$ with catalyst $(0.003 \mathrm{mmol})$ in toluene $(15 \mathrm{~mL})$. Aqueous phase: sodium acrylate $(3.3 \mathrm{mmol})$ and base: $\mathrm{Na}_{2} \mathrm{CO}_{3}(3.0 \mathrm{mmol})$ in water $(15 \mathrm{~mL})$; temperature: $150^{\circ} \mathrm{C}$; $1450 \mathrm{RPM}$; time: $0.5 \mathrm{~h}$; selectivity: $96-100 \%$. (The regioselectivity of all the

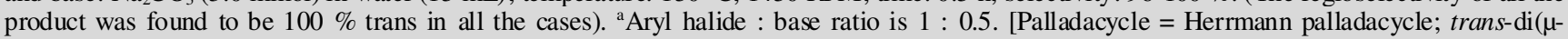
acetato)-bis[o-(di-o-tolylphosphino) benzyl]dipalladium(II); DPPE = Diphenyl phosphino ethane; $\mathrm{PPh}_{3}=$ Triphenyl phosphine; Bipy $=2,2$ Bipyridine; Py = Pyridine]; TON = Turn over number; TOF = Turn over frequency.

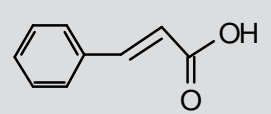

Cinnamic acid

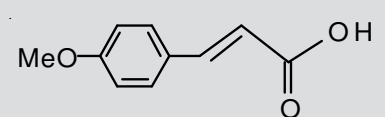

4-Methoxy cinnamic acid 2

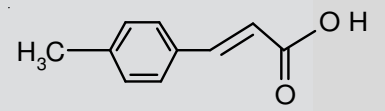

4-Methyl cinnamic acid 3 and hence the activity observed is comparable to the strength of the bases. When the base employed was carbonate or bicarbonate; carbon dioxide, commensurate to the conversion of iodobenzene was generated as seen from the increase in the pressure of reactor during the reaction.

The efficiency of the aqueous-organic biphasic system using palladacycle catalyst was assessed for the Heck vinylation of a variety of aryl halides, in presence of sodium carbonate as the base. The results are presented in Table-1 [Entry 5 and 13-16]. The iodoarenes were far more active than the bromoarenes, as expected from the literature reports ${ }^{27}$. The trends observed for the activities of aryl halides are also similar to those reported earlier for palladacycle catalysts ${ }^{4,5,26}$. Overall, the activity observed for the iodoarenes was lower in the biphasic medium as compared to those observed in homogeneous systems using the palladacycle catalyst. This is probably due to the poor solubility of the olefin in the catalyst phase, which is limiting. No reaction was observed with chlorobenzene using the biphasic catalysis proposed here [Table-1, entry 16].

In the aqueous-organic biphasic system developed in this work, the base employed is soluble in the aqueous phase, along with the base-halide adduct or salt formed. This leaves the catalyst phase free of any base or salt and hence can be recycled with ease. Also, since no thermal processing of any kind is required, the possibility for catalyst deactivation is minimized. The organic phase was separated and recycled to ascertain the stability and activity of the catalyst. As seen in Fig. 2, the catalyst could be recycled for four times with practically no loss in activity. The activity was enhanced for the first recycle from a turnover frequency (TOF) of $1784 \mathrm{~h}^{-1}$ to a TOF $2105 \mathrm{~h}^{-1}$

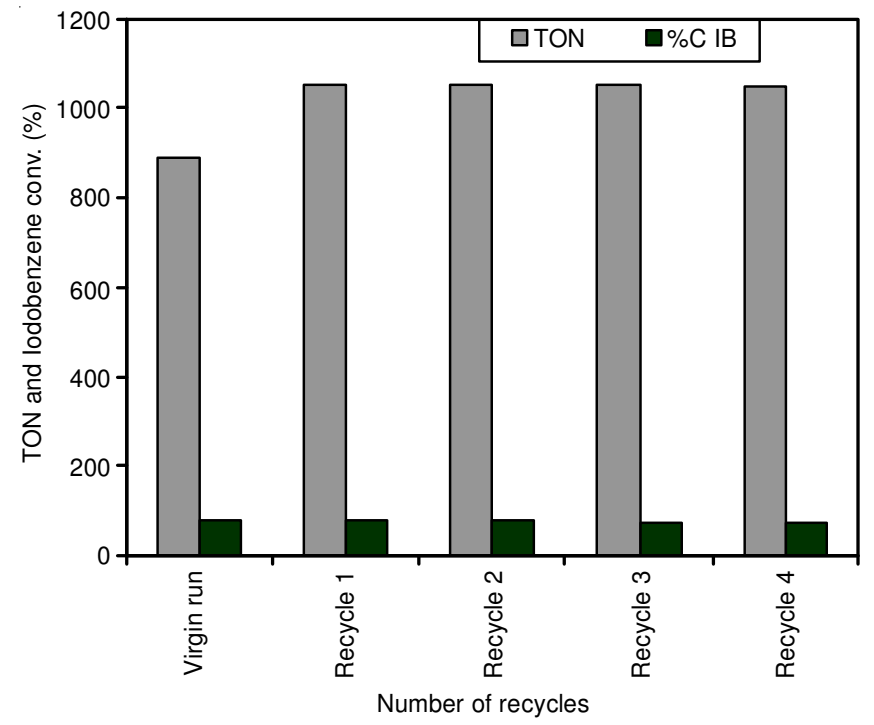

Fig. 2. Recycle studies using palladacycle catalyst in aqueous-org biphasic media. Reaction conditions: Organic phase: Iodobenzene (3.0 mmol) with palladacycle $(0.003 \mathrm{mmol})$ or recycled catalyst in toluene $(15 \mathrm{~mL})$. Aqueous phase: sodium acrylate $(3.3 \mathrm{mmol})$ and base: $\mathrm{NaHCO}_{3}(3.0 \mathrm{mmol})$ in water $(15 \mathrm{~mL})$. Temperature: $150{ }^{\circ} \mathrm{C}$; 1450 RPM; time: 0.5 h; selectivity: 96-100\%. [For recycle study, the catalyst phase (organic phase) was separated by simple phase separation and used (instead of fresh toluene) in the above procedure and fresh aqueous phase along with substrates and base were added during each recycle along with substrates]

and was almost constant for all four recycles. The iodobenzene conversion for the virgin reaction was ca. $80 \%$ and the residual iodobenzene was recycled along with fresh iodobenzene for the catalyst recycle, which accounts for enhanced turn over number (TON) for recycle. The results on catalyst recycle 
studies indicate that the catalyst is tolerant to water and can be recycled with ease. No leaching of the Pd complex to the aqueous phase was observed in the course of the recycle study.

It is known that palladacycle complex may degenerate to Pd metal under the reaction conditions used for Heck reaction ${ }^{28}$. However, reports by Herrmann and coworkers indicate that the palladacycle complex is stable in toluene under reflux even for few days ${ }^{26,29}$. It was hence of interest to see whether any decomposition of the catalyst was observed in the course of the reaction. No precipitation of Pd was observed, even at the end of four recycles. In the biphasic system proposed, the organic phase comprises toluene, palladacycle catalyst and the aryl halide. The sodium acrylate, product cinnamate and the base/base-HX adduct are present in water. As a result, the palladacycle has minimum exposure to these components. This may be the reason why the palladacycle is stable under reaction conditions in the biphasic medium used.

Since the objective of this work was to develop a strategy for the product separation and the catalyst recycle, a reaction was conducted to complete conversion of the iodobenzene. The concentration time profile for this experiment (organic phase profile) is shown in Fig. 3. At the end of the reaction, analysis of the organic phase showed negligible iodobenzene. The acidification of the aqueous phase gave quantitative formation of cinnamic acid. From this study it seems to be a feasible strategy to recycle the catalyst after total conversion of the halide. Residual sodium acrylate can also be recovered from the aqueous phase for further recycle. The use of the biphasic medium described above can thus provide an excellent methodology for the recycle of catalyst, separation of product and recycle of unreacted substrates, in the Heck coupling of water-soluble substrates. A high cumulative turn over number (TON) is achievable with the biphasic medium proposed. (Up to 5100 has been achieved after 4 recycles in this case).

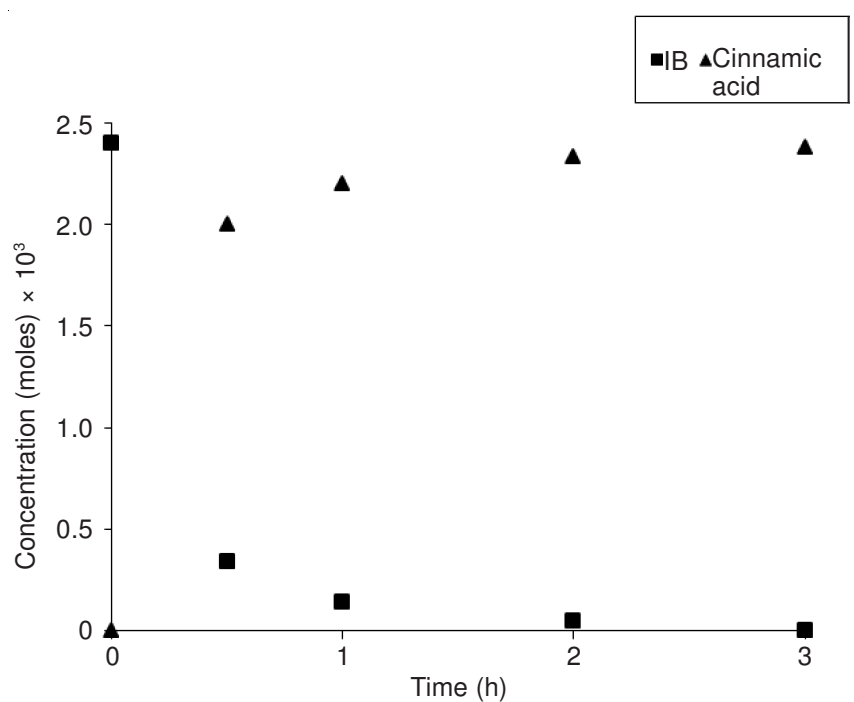

Fig. 3. Typical concentration profile for Heck reaction in aqueous biphasic medium using palladacycle catalyst. Reaction conditions: Organic Phase: Iodobenzene $(3.0 \mathrm{mmol})$ with palladacycle catalyst $(0.003$ $\mathrm{mmol})$ in toluene $(15 \mathrm{~mL})$. Aqueous phase: Sodium acrylate $(3.3$ $\mathrm{mmol})$ and base $\mathrm{Na}_{2} \mathrm{CO}_{3}(3.0 \mathrm{mmol})$ in water $(15 \mathrm{~mL})$. Temperature: $150{ }^{\circ} \mathrm{C}$; $1450 \mathrm{rpm}$; time: $0.5 \mathrm{~h}$; selectivity: $96-100 \%$
The idea of using such efficient catalyst in biphasic system is more useful through industrial point of view. The results produced here are of the reactions, those taken for very short time $(0.5 \mathrm{~h})$ and are just to show the feasibility of the use of catalyst in biphasic medium, however proper tailoring of reaction may still improve the activity.

\section{Conclusion}

The palladacycle catalyst efficiently catalyzes Heck coupling of acrylate salts with aromatic halides in a biphasic [aqueous-organic] medium. Sodium hydroxide, carbonate and bicarbonate were efficient although retained in the second, non-catalyst phase. The activity observed for the vinylation was highest for iodobenzene followed by bromobenzene. No reaction was observed with chlorobenzene. The palladacycle catalyst was stable in presence of water and could be recycled for four times with no loss in the activity. Such a system facilitates easy recycle of catalyst and also the removal of the salts from the catalyst phase, ensuring high activity with respect to cumulative turn over number and turn over frequency. The products which are cinnamic acid derivatives were soluble in water. The biphasic system developed has the following advantages (i) efficient catalyst recovery and recycle, (ii) convenient product separation and (iii) efficient removal of halide in water. Strategies for total conversion of halide followed by an efficient catalyst recycle, isolation of product and recovery of the unreacted sodium acrylate have been outlined.

GCMS analysis of the isolated products:

1. $m / z: 147\left(\mathbf{M}^{+}+1\right), 131,128,91,77,51$.

2. $m / z: 178\left(\mathrm{M}^{+}\right), 191,133,118,89,77,63,51$.

3. $m / z: 162\left(\mathrm{M}^{+}+1\right), 147,115,91,44$.

\section{ACKNOWLEDGEMENTS}

One of the authors (S.V. Jagtap) thank University Grant Commission of India for providing the Ph.D. fellowship.

\section{REFERENCES}

1. G.W. Parshall, Homogeneous Catalysis, Wiley Interscience, New York (1980).

2. E.G. Kuntz, Chemtech, 17, 570 (1987).

3. B.M. Bhanage and M. Arai, Catal. Rev., 43, 315 (2001).

4. W.A. Herrmann, C. Brossmer, K. Ofele, C.-P. Reisinger, T. Priermeir, M. Beller and H. Fischer, Angew. Chem. Int. Ed., 34, 1844 (1995).

5. W.A. Herrmann, C. Brossmer, C.-P. Reisinger, T.H. Riermeier, K. Ofele and M. Beller, Chem. Eur. J., 3, 1357 (1997).

6. B.M. Bhanage, F.G. Zhao, M. Shirai and M. Arai, Tetrahedron Lett., 39, 9509 (1998).

7. M. Beller, J.G.E. Krauter and A. Zapf, Angew. Chem. Int. Ed., 36, 772 (1997).

8. T. Thorpe, S.M. Brown, J. Crosby, S. Fitzjohn, J.P. Muxworthy and J. M.J. Williams, Tetrahedron Lett., 41, 4503 (2000).

9. R.B. DeVasher, L.R. Moore and K.H. Shaughnessy, J. Org. Chem., 69, 7919 (2004).

10. D.B.G. Williams, H. Lombard and C.W. Holzapfel, Synth. Commun., 31, 2077 (2001).

11. S.V. Jagtap and R.M. Deshpande, Catal. Today, 131, 353 (2008).

12. N.A. Bumagin, P.G. More and I.P. Beletskaya, J. Organomet. Chem., 371, 397 (1989).

13. A.C. Casalnuovo and J.C. Calabrese, J. Am. Chem. Soc., 112, 4324 (1990).

14. J.P. Genet, E. Blart and M. Savignac, Synlett, 715 (1992).

15. T. Jeffery, Tetrahedron Lett., 35, 3051 (1994).

16. J.P. Genet and M. Savignac, J. Organomet. Chem., 576, 305 (1999).

17. F.E. Herkes, A. Eisenstadt, Catalysis of Organic Reactions, Marcel Dekker, New York, p. 415 (1998). 
18. O. Arrad and Y. Sasson, J. Am. Chem. Soc., 110, 185 (1988).

19. E.V. Dehmlow and S.S. Dehmlow, Phase Transfer Catalysis, VCH Weinheim, New York and references cited, edn. 3 (1993).

20. I.P. Beletskaya and A.V. Cheprakov, Chem. Rev., 100, 3009 (2000).

21. D. Garbe, W. Gerhartz, J.S. Yamamoto, I.T. Campbell, R. Pfefferkorn and J.F Rounsville, Ullmann's Encyclopaedia of Industrial Chemistry, Vol. A7, 99, VCH: Weinheim (1992).

22. F. Natella, M. Nardini, M. Di Felice and C. Scaccini, J. Agric. Food Chem., 47, 1453 (1999).

23. S. Adisakwattana, K. Sookkongwaree, S. Roengsumran, A. Petsom, N. Ngamrojnavanich, W. Chavasiri, S. Deesamer and S. Yibchok-anun, Bioorg. Med. Chem. Lett., 14, 2893 (2004).
24. B.J. McCormick, E.N. Jaynes Jr. and R.I. Kaplan, Inorg. Synth., 13, 216 (1972).

25. S. Komiya, Synthesis of Organometallic Compounds-A Practical Guide (1997).

26. W.A. Herrmann, V.P.W. Bohm and C.-P. Reisinger, J. Organomet. Chem., 576, 23 (1999).

27. C.S. Consorti, M.L. Zanini, S. Leal, G. Ebeling and J. Dupont, Org. Lett., 5, 983 (2003)

28. I.P. Beletskaya and A.V. Cheprakov, J. Organomet. Chem., 689, 4055 (2004).

29. W.A. Herrmann, K.O fele, D.V. Preysing and S.K. Schneider, J. Organomet. Chem, 687, 229 (2003). 